\title{
Outcome of Transurethral Plasmakinetic Vaporization for Benign Prostatic Hyperplasia
}

\author{
Magdy El-Tabey ${ }^{1}$, Ahmed Abo-Taleb ${ }^{1}$, Ashraf Abdelal ${ }^{1}$, Mostafa Mahmod Khalil ${ }^{1}$ \\ ${ }^{1}$ Department of Urology Benha Faculty of Medicine, Benha, Egypt
}

\section{ABSTRACT}

Purpose: To assess the outcome of transurethral plasmakinetic vaporization (PKVP) in the management of benign prostatic hyperplasia (BPH).

Patients and methods: From August 2010 to May 2012, 60 patients with obstructive LUTS due to BPH were included in the study. All patients were evaluated by International Prostate Symptom Score (IPSS), general examination, digital rectal examination, PSA, routine laboratory examinations, pelvi-abdominal ultrasound, trans-rectal ultrasound, and uroflowmetry. Patients with Qmax of $<10 \mathrm{~mL} / \mathrm{sec}$., an IPSS of $>8$ and a prostate volume of $>40 \mathrm{~mL}$ underwent transurethral PKVP.

Results: Mean age of the patients was $66.8 \pm 4.5$ years. The mean times of the operation, post-operative bladder irrigation, and post-operative catheterization were $63.8 \pm 13.9$ minutes, $15.2 \pm 5.7$ hours, and 23.9 \pm 5.2 hours, respectively. At 3 months of follow-up, there were significant reductions in the mean IPSS from $23.4 \pm 3.5$ to $9.2 \pm 3.7(P=0.4)$, mean PSA from $3.03 \pm 2.2 \mathrm{ng} / \mathrm{mL}$ to $1.2 \pm 1.04 \mathrm{ng} / \mathrm{mL}$ ( $\mathrm{P}$ value $=0.02$ ), mean post voiding residual urine from $149.8 \pm 59.5 \mathrm{~mL}$ to $46.9 \pm 24.1 \mathrm{~mL}$ (P value $<0.01$ ), and mean prostate volume from $72.8 \pm 10.3 \mathrm{~mL}$ to $22.7 \pm 6.1 \mathrm{~mL}$ (P value $<0.01$ ).

Also, there was a statistically significant increase in the mean $Q$ max. from $8.7 \pm 2.4$ $\mathrm{mL} / \mathrm{s}$ to $19.5 \pm 3.5 \mathrm{~mL} / \mathrm{s}$ (P value $<0.01)$.

Conclusion: PKVP is an effective and safe treatment option in the management of symptomatic BPH.
\end{abstract}

\section{ARTICLE INFO}

\section{Key words:}

Prostatic Hyperplasia;

Transurethral Resection of

Prostate; Prostatectomy

Int Braz J Urol. 2015; 41: 239-44

Submitted for publication:

August 11, 2013

Accepted after revision:

June 23, 2014

\section{INTRODUCTION}

Benign prostatic enlargement represents a significant health problem in aged males due to its negative impact on the health related quality of life; medical therapy of the prostate improved patients' symptoms but yielded the presentation of large-sized prostates (1).

The conventional standard monopolar transurethral resection of the prostate (TURP) is still the first-line treatment option for surgical management of BPH sized from 30 to $80 \mathrm{~mL}$ and this modality still have 18\% morbidity and $0.2 \%$ mortality rate (2).
With the advancement in the bipolar technology, the popularity of transurethral electro-vaporization of the prostate has been increased, especially after the development of the Gyrus ${ }^{\circledR}$ PlasmaKinetic ${ }^{\circledR}$ Tissue Management System (Gyrus Medical Ltd, Bucks, UK) (3). In 2009 the European Association of Urology recommended transurethral plasmakinetic vaporization of the prostate (PKVP) as an alternative to the conventional monopolar TURP with promising initial reports of lower morbidity and similar efficacy and durability (4). In the current study, the technique of PKVP was evaluated regarding its efficacy, safety, and morbidity. 


\section{MATERIALS AND METHODS}

From August 2010 till May 2012, 60 patients with obstructive LUTS due to BPH were enrolled in the study. All patients were evaluated by International Prostate Symptom Score (IPSS), general examination, digital rectal examination (DRE), PSA, serum biochemistry, coagulation profile, urine culture and sensitivity, pelvi-abdominal ultrasound, trans-rectal ultrasound (TRUS) , and uroflowmetry. The inclusion criteria were recurrent urinary retention in spite of medical treatment, maximum flow rate ( $\mathrm{Q}$ max.) of $<10 \mathrm{~mL} / \mathrm{se}-$ cond, IPSS of $>20$. Patients with previous prostate or urethral surgery, prostate cancer, or neurogenic bladder were excluded from the study.

The procedure with its benefits and all possible complications was explained to the patients and a written consent was signed by all patients, and the study was approved by the Local Ethics and Research Committee.

\section{TECHNIQUE}

Several prostatic fragments were resected first by standard TURP for pathological examination. Transurethral plasmakinetic vaporization of the prostate (PKVP) was carried out using the Olympus SurgMaster (Tokyo,Japan) bipolar high frequency generator, with special 'mushroom' shape vapo-resection electrode and isotonic 0.9\% sodium chloride (saline) as an irrigating fluid.

The spherical shape of the new type of electrode displaying a plasma corona on its surface was gradually moved into direct contact with the BPH tissue (the 'hovering' technique), thus producing a virtually bloodless vaporization in 280-320 W.

The procedure was performed like a TURP, starting at the bladder neck (Figure-1), then continuing to the lateral lobes (Figure-2) and finally to the apical portion of the prostate. After finishing at the level of the capsular fibers, a transurethral resection like cavity was obtained (Figure-3). Coagulation of any hemorrhagic sources was practically concomitant. In all cases, a 20 F Foley's catheter was placed at the end of the procedure. Continuous bladder irrigation was necessary until hematuria sufficiently resolved.
Figure 1 - Initiation of the transurethral PKVP.

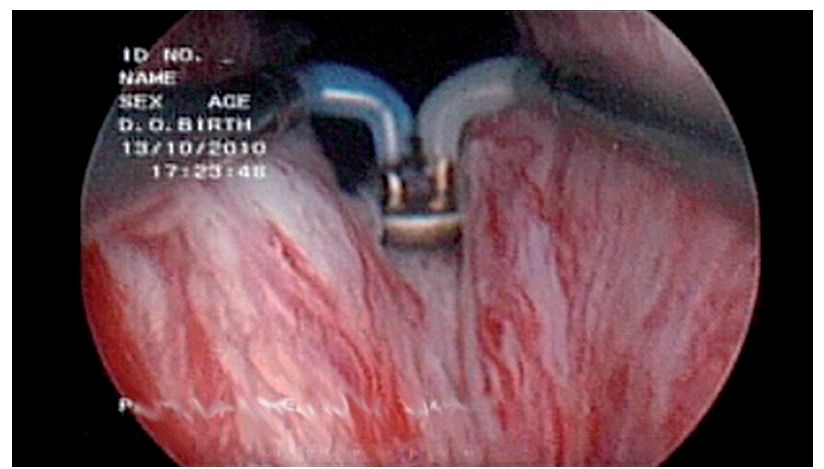

Figure 2 - Transurethral PKVP of the right lobe of the prostate.

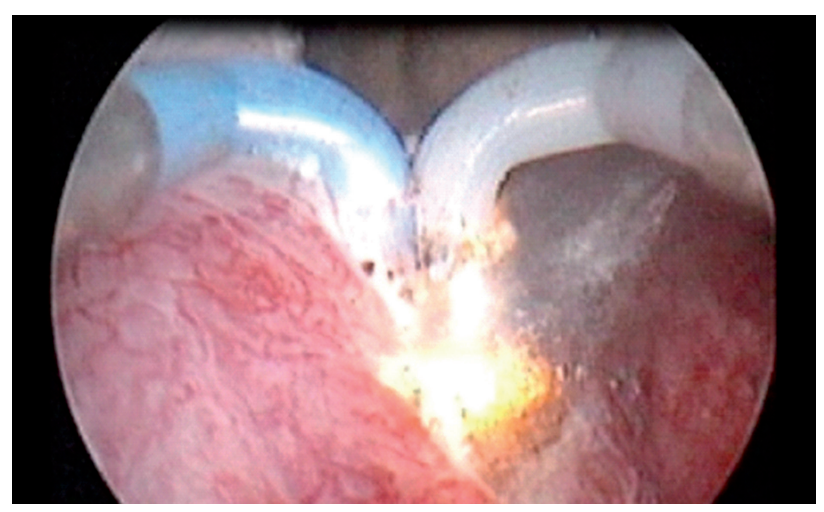

Figure 3 - At the end of the procedure and cavity formation.

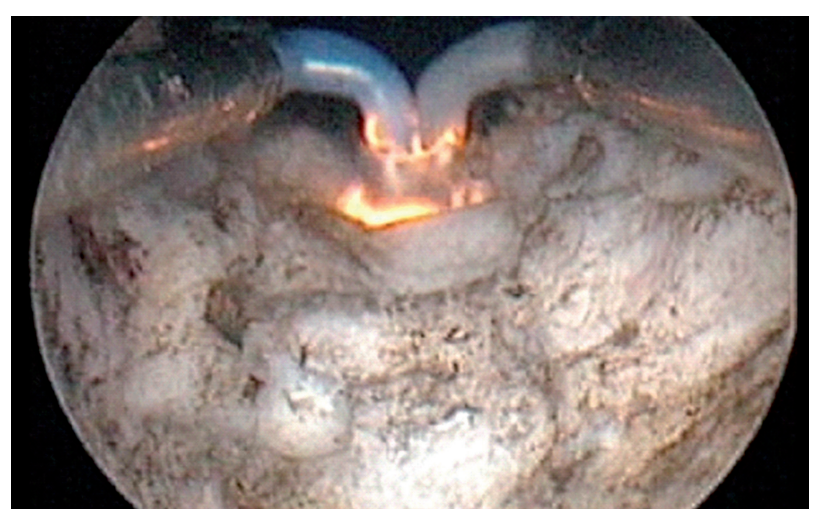

Intra-operative, immediate post-operative data and complications were recorded. After 3 months, all patients were assessed by the PSA level, IPSS, uroflowmetry, post-voiding residual urine volume estimation, and prostate size estimation by TRUS. All data were tabulated and statistically 
analyzed using SPSS ver. 16 software, $\mathrm{P}$ values were estimated and considered statistically significant if $<0.05$.

\section{RESULTS}

In the current study, the mean age of the patients was $66.8 \pm 4.5$ years. The mean pre-operative serum PSA level was $3.03 \pm 2.2 \mathrm{ng} / \mathrm{mL}$. In 12 patients $(20 \%)$, the serum PSA levels were more than $4 \mathrm{ngl} / \mathrm{mL}$, and all of them showed a negative result for malignancy in TRUS prostatic biopsy before inclusion in the study.

The mean operative time was $63.8 \pm 13.9 \mathrm{mi}-$ nutes, the mean post-operative bladder irrigation time was $15.2 \pm 5.7$ hours, and the mean post-operative catheterization time was $23.9 \pm 5.2$ hours.

The operative and postoperative data are shown in Table-1.

Immediate post-operative period showed no significant changes between the mean pre-operative hemoglobin $(12.7 \pm 1.06 \mathrm{~g} / \mathrm{dL})$ and serum $\mathrm{Na}(139.7 \pm 3.5 \mathrm{mmol} / \mathrm{l})$ and the post-operative values $(11.8 \pm 0.9 \mathrm{~g} / \mathrm{dL}$ and $(139.1 \pm 5.5 \mathrm{mmol} / \mathrm{L})$, respectively. At 3 months of follow-up, there was a decrease in the mean IPSS from $23.4 \pm 3.5$ pre-operatively to $9.2 \pm 3.7$, however, this decrease was statistically non-significant $(P$ value $=0$. 4). There was statistically significant decrease in the mean PSA from $3.03 \pm 2.2 \mathrm{ng} / \mathrm{mL}$ to $1.2 \pm 1.04$ $\mathrm{ng} / \mathrm{mL}$ ( $\mathrm{P}$ value $=0.02$ ), mean post voiding residual urine from $149.8 \pm 59.5 \mathrm{~mL}$ to $46.9 \pm 24.1 \mathrm{~mL}$ $(P$ value $=0.01)$, and mean prostate volume from $72.8 \pm 10.3 \mathrm{~mL}$ to $22.7 \pm 6.1 \mathrm{~mL}(P$ value $=0.01)$. Also, there was a statistically significant increase in the mean $Q \max$ from $8.7 \pm 2.4 \mathrm{~mL} / \mathrm{s}$ to $19.5 \pm 3.5$ $\mathrm{mL} / \mathrm{s}(P$ value $=0.01)$.

The post-operative complications are shown in Table-2. There was persistent hematuria developed in two patients (3.3\%) that resolved spontaneously on the first postoperative month. Transient mild to moderate dysuria was reported in 6 patients $(10 \%)$, and resolved with medications within 2 weeks. Urinary tract infection with positive urine culture occurred in 20\% of cases, treated with proper antimicrobial drugs. Seven patients (11.7\%) presented with severe obstructive LUTS within 10 days post surgical which were dealt with catheterization for one week then catheter removed and all patients voided normally.

No patients developed acute urine retention or secondary hemorrhage. Blood transfusion was not needed and no postoperative clot retention was reported. No reoperation was required and no incontinence or TUR syndrome appeared.

\section{DISCUSSION}

Currently, the classic TURP is still the gold standard minimally invasive treatment for $\mathrm{BPH}$,

Table 1 - Pre-operative and post-operative data of the patients.

\begin{tabular}{|c|c|c|c|}
\hline & Pre-operative data & Post-operative data & P-value \\
\hline \multicolumn{4}{|l|}{ Immediate post-operative } \\
\hline Mean $\mathrm{Hb}(\mathrm{g} / \mathrm{dL})$ & $12.7 \pm 1.06$ & $11.8 \pm 0.9$ & 0.15 \\
\hline Mean Na (mmol/L) & $139.7 \pm 3.5$ & $139.1 \pm 5.5$ & 0.52 \\
\hline \multicolumn{4}{|l|}{3 month post-operative } \\
\hline Mean IPSS & $23.4 \pm 3.5$ & $9.2 \pm 3.7$ & 0.4 \\
\hline Mean PSA (ng/mL) & $3.03 \pm 2.2$ & $1.2 \pm 1.04$ & 0.02 \\
\hline Mean prostate vol.(mL) & $72.8 \pm 10.3$ & $22.7 \pm 6.1$ & 0.01 \\
\hline Mean residual urine $(\mathrm{mL})$ & $149.8 \pm 59.5$ & $46.9 \pm 24.1$ & 0.01 \\
\hline Mean Qmax. (mL/sec.) & $8.7 \pm 2.4$ & $19.5 \pm 3.5$ & 0.01 \\
\hline
\end{tabular}


Table 2 - Complications.

\begin{tabular}{lc}
\hline Item & $\mathrm{N}=60$ \\
\hline Hematuria: No. (\%) & $2(3.3)$ \\
Irritative symptoms: No. (\%) & $6(10)$ \\
UTI: No. (\%) & $12(20)$ \\
Obstructive urinary symptoms: No. (\%) & $7(11.7)$ \\
Clot retention: No. (\%) & $0(0)$ \\
Secondary hemorrhage: No. (\%) & $0(0)$ \\
Re-operation: No. (\%) & $0(0)$ \\
TUR syndrome: No. (\%) & $0(0)$ \\
\hline
\end{tabular}

however many alternative treatment modalities have been developed recently aiming to reduce the $18 \%$ early post-operative morbidity and the $0.2 \%$ intra-operative mortality (2). Plasmakinetic technology in resection is one of the recent minimally invasive treatment options for BPH with an efficiency similar to that of TURP (5).

During PKVP there is a significant reduction in the stages of the conventional TURP due to concomitant vaporization and hemostasis, and quick evacuation of the few resected tissue fragments so there is less operative time than in TURP (3).

In the study of Engeler et al., the mean duration of surgery was 50 minutes (6), and in the studies of Zhang et al. (7), and Ahyai et al. (8), the operative time was $39 \pm 15.5$ minutes and 36 minutes, respectively. The relatively longer operative time in the current study (63.8 \pm 13.9 minutes) might be due to the stepwise learning curve, as the mean operative time in the first thirty patients was $71.5 \pm 14.02$ minutes and in the second half of patients was $56 \pm 8.7$ minutes.

As regard to catheter removal, our results were comparable to the results of Reich et al., where the mean catheterization time was 41 hours (9), and in the study of Ahyai et al., the catheter was removed after a mean of 1.3 days after bipolar vaporization (8).

In the current study there was no statistically significant difference between the pre- -operative and post-operative mean hemoglobin values, there was a minimal drop in the mean hemoglobin value of nearly $0.9 \mathrm{~g} / \mathrm{dL}$. This was comparable to many recent studies that found that the mean reduction in hemoglobin was $0.6 \mathrm{~g} / \mathrm{dL}$ (3), $0.3 \mathrm{~g} / \mathrm{dL}(6)$ and $0.8 \mathrm{gm} / \mathrm{dL}$ in the study of Hon et al. (10). Gilling and associates added that due to the excellent haemostasis of vaporization, this technique could be specially if not solely indicated for patients at high risk of bleeding and those receiving oral anticoagulants (11).

TUR syndrome is the most important complications of TURP that may develop in 2\% of patients submitted to TURP (2) as a result of hyponatremia with the use of glycine solution that enters the vascular circulation due to open vessels or periprostatic extravasation (12). This risk was eliminated with bipolar plasmakinetic technology, because of usage of isotonic saline solution for irrigation (4-8). In our study, the immediate decrease in postoperative serum $\mathrm{Na}$ level was statistically insignificant $(\mathrm{P}=0.52)$, so TUR syndrome was not an issue in the present study; this was in agree with many previously published studies (4-8).

In the current study, the mean size of the prostate was statistically significantly decreased when measured by TRUS after 3 month from PKVP $(\mathrm{P}=0.01)$.These results were consistent with many recent studies. In the study of Geavlete et al. (3) the mean preoperative prostate volume was $56.2 \mathrm{~mL}$ that reduced to $16.8 \mathrm{~mL}$, when estimated at 6 months postoperative. In the study of Nuhoglu et al. (13) mean preoperative prostate volume was $47 \pm 7.7 \mathrm{~mL}$ that was significantly reduced to $22 \pm 6.8 \mathrm{~mL}$ after one year, and in the study of Liu et al. (14) mean preoperative prostate volume was $67.7+12$ gm (range 35 to 256 ) and the mean resected volume was $42.8+7.7 \mathrm{gm}$ (range 23 to 219) using plasmakinetic technology.

Generally, there is significant decrease of the pre-operative serum PSA levels at 3 months after the conventional TURP and open prostatectomy (15),and in the current study, the decrease in the mean PSA level at 3 months follow-up was statistically significant $(\mathrm{P}=0.02)$. This is in agree with the result of Geavlete et al. (3), as they reported a significant decrease of the mean pre-operative PSA from $1.82 \mathrm{ng} / \mathrm{mL}$ to a mean of $1.1 \mathrm{ng} / \mathrm{mL}$, 
$0.93 \mathrm{ng} / \mathrm{mL}$, and $0.74 \mathrm{ng} / \mathrm{mL}$ at 1,3,and 6 months follow-up, respectively.

In the current study there was statistically significant increase in the mean $\mathrm{Qmax}(\mathrm{P}=0.01)$, and another statistically significant decrease in the mean post voiding residual urine $(\mathrm{P}=0.01)$ at 3 months follow-up. We founded also improvement in the mean IPSS at 3 months follow-up, however it was statistically not significant $(\mathrm{P}=0.4)$.

There are many studies supporting the significant improvement in the previous parameters after PKVP. Talic et al. found improvement in IPSS from 24.9 to $4 \pm 3.4$ and $Q \max$ from 7.5 to $19 \pm 6.5$ $\mathrm{mL} / \mathrm{sec}$.(16), and Nuhoglu et al. (13) reported improvements in IPSS from $17.6 \pm 6.1$ to $4.8 \pm 3.4$, Q $\max$ of $6.9 \pm 2.8 \mathrm{~mL} / \mathrm{s}$ to $17.6 \pm 4.3 \mathrm{~mL} / \mathrm{s}$, and decrease in the mean post voiding residual urine from $96 \pm 27 \mathrm{~mL}$ to $27 \pm 17 \mathrm{~mL}$ at 1 month follow-up.

In the present study, persistent hematuria developed in two patients (3.3\%) that recovered in the first postoperative month without the need of any treatment.

Blood transfusion was not needed and no post-operative clot retention occurred. No reoperation was required in our short term follow-up while in the study of Karaman et al., they reported $12 \%$ incidence of reoperation but after 3 years of follow-up (17). No incontinence or meatal stenosis appeared despite the use of a 27-Fr. resectoscope.

Dysuria and frequency as post-operative irritative symptoms were reported in $10 \%$ of cases and responded well to antimuscarinic treatment; this relative high rate was probably as a result of oedema secondary to higher current with lower frequency exerted on the tissues as claimed by Tefekli et al. (18); however, Singh and his colleagues reported that postoperative dysuria was less intense with bipolar TURP that could be attributed to the greater thermal damage and formation of granulation tissue with monopolar current (19). Ahyai and associates reported a fairly high rate of transient dysuria 8.3\% which looks like a characteristic adverse event after bipolar vaporization (8). There were 7 patients (11.7\%) presented with severe obstructive LUTS with significant high post voiding residual urine in the first 10 post-operative days which were dealt with by catheterization for one week, then all patients voided normally after catheter removal. This higher recatherization rate with the bipolar device was also described in a randomized study of Dunsmuir et al. (12) ,and in a study of Reich et al.: 13\% of patients were recatheterized temporarily in less than 24 hours after initial catheter removal (9).

\section{CONCLUSIONS}

The initial short-term results of PKVP shows good efficacy, reduced morbidity and fast recovery, early postoperative urethral catheter removal, a shorter hospital stay and the absence of TUR syndrome risk. Despite these very promising initial short-term results, long-term studies assessing the durability are mandatory to confirm the superiority of PKVP over TURP as a primary treatment option in BPH.

\section{CONFLICT OF INTEREST}

None declared.

\section{REFERENCES}

1. Carter HB, Coffey DS. The prostate: an increasing medical problem. Prostate. 1990;16:39-48.

2. Mebust WK, Holtgrewe HL, Cockett AT, Peters PC. Transurethral prostatectomy:immediate and postoperative complications. A cooperative study of 13participating institutions evaluating 3,885 patients. J Urol. 1989;141:2437.

3. Geavlete B, Multescu R, Dragutescu M, Jecu M, Georgescu $D$, Geavlete P. Transurethral resection (TUR) in saline plasma vaporization of the prostate VS standard TUR of the prostate: 'the better choice' in benign prostatic hyperplasia? BJU Int. 2010:1695-9.

4. M. Oelke (chairman), G. Alivizatos, M. Emberton, S. Gravas, S. Madersbacher, M. Michel, J. Nordling, C. Rioja Sanz, J. de la Rosette Guidelines on benign prostatic hyperplasia. In Parsons KF, Irani J, Chapple CR et al. eds. European Association of Urology Pocket Guidelines, Arnhem: European Association of Urology, 2009: 90-7.

5. Eaton AC, Francis RN. The provision of transurethral prostatectomy on a day-case basis using bipolar plasma kinetic technology. BJU Int. 2002;89:534-7.

6. Engeler DS, Schwab C, Neyer M, Grün T, Reissigl A, Schmid HP. Bipolar versus monopolar TURP: a prospective controlled study at two urology centers. Prostate Cancer Prostatic Dis. 2010;13:285-91. 
7. Zhang SY, Hu H, Zhang XP, Wang D, Xu KX, Na YQ, et al. Efficacy and safety of bipolar plasma vaporization of the prostate with "button-type" electrode compared with transurethral resection of prostate for benign prostatic hyperplasia. Chin Med J (Engl). 2012;125:3811-4.

8. Ahyai SA, Gilling P, Kaplan SA, Kuntz RM, Madersbacher S, Montorsi F, et al. Meta-analysis of functional outcomes and complications following transurethral procedures for lower urinary tract symptoms resulting from benign prostatic enlargement. Eur Urol. 2010;58:384-97.

9. Reich 0, Schlenker B, Gratzke C, Tilki D, Riecken M, Stief $\mathrm{C}$, et al. Plasma vaporisation of the prostate: initial clinical results. Eur Urol. 2010;57:693-7.

10. Hon NH, Brathwaite D, Hussain Z, Ghiblawi S, Brace H, Hayne D, et al. A prospective, randomized trial comparing conventional transurethral prostate resection with PlasmaKinetic vaporization of the prostate: physiological changes, early complications and long-term followup. J Urol. 2006;176:205-9.

11. Gilling PJ, Aho TF, Frampton CM, King CJ, Fraundorfer MR. Holmium laser enucleation of the prostate: results at 6 years. Eur Urol. 2008;53:744-9.

12. Dunsmuir WD, McFarlane JP, Tan A, Dowling C, Downie $J$, Kourambas J, et al. Gyrus bipolar electrovaporization vs transurethral resection of the prostate: a randomized prospective single-blind trial with 1 y follow-up. Prostate Cancer Prostatic Dis. 2003;6:182-6.

13. Nuhoğlu B, Ayyildiz A, Karagüzel E, Cebeci 0 , Germiyanoğlu C. Plasmakinetic prostate resection in the treatment of benign prostate hyperplasia: results of 1-year follow up. Int J Urol. 2006;13:21-4.
14. Liu C, Zheng S, Li H, Xu K. Transurethral enucleation and resection of prostate in patients with benign prostatic hyperplasia by plasma kinetics. J Urol. 2010;184:2440-5.

15. Furuya $Y$, Akakura $K$, Tobe $T$, Ichikawa $T$, Igarashi $T$, Ito $\mathrm{H}$. Changes in serum prostate-specific antigen following prostatectomy in patients with benign prostate hyperplasia. Int J Urol. 2000;7:447-51.

16. Talic RF, El Tiraifi A, El Faqih SR, Hassan SH, Attassi RA, Abdel-Halim RE. Prospective randomized study of transurethral vaporization resection of the prostate using the thick loop and standard transurethral prostatectomy. Urology. 2000;55:886-90; discussion 890-1.

17. Karaman MI, Kaya C, Ozturk M, Gurdal M, Kirecci S, Pirincci N. Comparison of transurethral vaporization using PlasmaKinetic energy and transurethral resection of prostate: 1-year follow-up. J Endourol. 2005;19:734-7.

18. Tefekli A, Muslumanoglu AY, Baykal M, Binbay M, Tas A, Altunrende F. A hybrid technique using bipolar energy in transurethral prostate surgery: a prospective, randomized comparison. J Urol. 2005;174:1339-43.

19. Singh H, Desai MR, Shrivastav P, Vani K. Bipolar versus monopolar transurethral resection of prostate: randomized controlled study. J Endourol. 2005;19:333-8.

\footnotetext{
Correspondence address:

Mostafa Mahmod Khalil, MD

Benha Faculty of medicine - Urology

Farid Nada ,St. Benha 5321, Egypt

Telephone: +20 109 900-4101

E-mail: mostafa.mahmod@gmail.com
} 